\title{
Distribution and Coordination State of Titanium Oxides in Microstructures Formed by Spinodal Decomposition in Multicomponent Borosilicate Glass
}

\author{
Masanori SUZUKI ${ }^{1)}$ and Toshihiro TANAKA ${ }^{21}$ \\ 1) Research Fellow of the Japan Society for the Promotion of Science, Division of Materials and Manufacturing Science, \\ Graduate School of Engineering, Osaka University, 2-1 Yamadaoka, Suita, Osaka 565-0871 Japan. \\ 2) Division of Materials and Manufacturing Science, Graduate School of Engineering, Osaka University, 2-1 Yamadaoka, Suita, \\ Osaka 565-0871 Japan.
}

(Received on November 16, 2009; accepted on January 25, 2010)

\begin{abstract}
Tetrahedrally coordinated titanium oxides implanted into inorganic materials aid in the removal of air-based pollutants by photocatalytic reactions. We investigated the distribution and the coordination state of titanium oxides in a phase-separated glass formed by the spinodal decomposition to obtain porous glass containing tetrahedrally coordinated titanium oxides. Various glass compositions containing titanium oxides were prepared by partially replacing $\mathrm{SiO}_{2}$ with $\mathrm{B}_{2} \mathrm{O}_{3}$ and small amounts of $\mathrm{TiO}_{2}$ in multicomponent silicate glass compositions where a spinodal decomposition had been confirmed. Interconnected microstructures that consist of two different phases were observed in heat-treated glass samples using transmission electron microscopy and these microstructures underwent spinodal decomposition. Compositional analyses of these microstructures using energy dispersion spectroscopy revealed that the decomposed phase with higher concentration of $\mathrm{SiO}_{2}$ contains smaller amount of titanium oxides than the other phase. Thermodynamic analysis was conducted to evaluate the distribution of titanium oxides in the glass phases, formed by a phase separation in the multicomponent borosilicate glass, where glass was regarded as a super-cooled liquid phase. In the thermodynamic analysis, the calculated activity of $\mathrm{TiO}_{2}$ in the two decomposed glass phases indicated that the glass phase with higher concentration of $\mathrm{SiO}_{2}$ contains lower concentration of titanium oxides. Porous glasses containing titanium oxide were fabricated from the spinodal-decomposed borosilicate glass by leaching one of the separated phases with an acid solution. Ti K-edge X-ray absorption near edge structure spectra indicated that the porous glass contains tetrahedrally coordinated titanium oxides.
\end{abstract}

KEY WORDS: tetrahedrally coordinated titanium oxide; phase separation; porous glass; Gibbs energy; super-cooled liquid phase.

\section{Introduction}

Spinodal decomposition has previously been investigated for various kinds of oxide glasses. ${ }^{1-4)}$ In this phase separation, a three-dimensional interconnected microstructure is formed by two different glass phases. The preparation of porous glass by spinodal decomposition has been carried out for several oxide glasses by leaching out one of the decomposed phases with an acid solution. ${ }^{3,4)}$ Since pore size can be controlled at the nanoscale, the porous glass is expected to have widespread application; for example, as filters to remove impurities from polluted water or air.

To fabricate porous glass materials from the waste slag discharged by metallurgical and waste incineration processes, we have developed a method to predict the phase separation in multicomponent oxide glass containing the fundamental components in slag. ${ }^{5-8)}$ In our previous studies, thermodynamic analyses were conducted to predict the composition ranges for spinodal decomposition in the $\mathrm{SiO}_{2}-\mathrm{CaO}-$
$\mathrm{Al}_{2} \mathrm{O}_{3}-\mathrm{Na}_{2} \mathrm{O}$ system where glass was regarded as a supercooled liquid phase. Spinodal decomposition was detected in the glass with a composition of $80.8 \mathrm{SiO}_{2}-11.5 \mathrm{CaO}-$ $2.5 \mathrm{Al}_{2} \mathrm{O}_{3}-5.0 \mathrm{~mol} \% \mathrm{Na}_{2} \mathrm{O}$, which is included in the calculated metastable miscibility gap. ${ }^{7,8)}$ The above glass composition is referred to as glass $\mathrm{A}$ in this paper.

To selectively dissolve one of the separated phases into an acid solution, we produced a multicomponent borosilicate glass A-1, $59.7 \mathrm{SiO}_{2}-13.8 \mathrm{CaO}-2.9 \mathrm{Al}_{2} \mathrm{O}_{3}-5.9 \mathrm{Na}_{2} \mathrm{O}-$ $17.7 \mathrm{~mol} \% \quad \mathrm{~B}_{2} \mathrm{O}_{3}$ by substituting $30 \mathrm{~mol} \%$ of $\mathrm{SiO}_{2}$ with $\mathrm{BO}_{1.5}$ in the $\mathrm{SiO}_{2}-\mathrm{CaO}-\mathrm{Al}_{2} \mathrm{O}_{3}-\mathrm{Na}_{2} \mathrm{O}$ glass $\mathrm{A} .^{7,8)}$ An interconnected morphology was observed in the borosilicate glass after annealing, and this indicated spinodal decomposition. Since one of the separated phases contained high proportion of $\mathrm{B}_{2} \mathrm{O}_{3}$, a glass with a three-dimensional porous structure was successfully obtained after removing this phase with an acid solution.

In the present study, we investigate the distribution of titanium oxides in the glass phases formed by the spinodal 
decomposition of multicomponent borosilicate glass to create porous glass containing tetrahedrally coordinated titanium oxides. It has previously been found that tetrahedrally coordinated titanium oxides can be implanted into microporous zeolite or mesoporous silica materials and that they can play a significant role in various photocatalytic reactions, including the removal of air pollutants. ${ }^{9)}$ Therefore, the spinodal decomposition of glass containing titanium oxides can be used to fabricate bulky porous glass materials for environmental purification while zeolites and mesoporous silica materials are generally obtained in the powder state by the sol-gel method.

It is expected that if titanium oxides have a tetrahedral coordination state in silicate glass, they can be partially replaced with $\mathrm{SiO}_{2}$ in a glass matrix structure. In this paper, several multicomponent borosilicate glass compositions containing titanium oxides were designed by partially substituting $\mathrm{SiO}_{2}$ with $\mathrm{B}_{2} \mathrm{O}_{3}$ and $\mathrm{TiO}_{2}$ in the multicomponent silicate glass composition $\mathrm{A}$, where spinodal decomposition had been observed. We investigated the distribution of titanium oxides in decomposed glass phases by compositional analyses of the microstructures obtained by spinodal decomposition in the borosilicate glasses. Thermodynamic analysis was used to evaluate the distribution of titanium oxides in the decomposed glass phases, where glass was regarded as a super-cooled liquid phase. Porous glasses were then produced by leaching one of the decomposed phases in these borosilicate glasses with acid solutions. The coordination state of titanium oxides in these porous glasses was examined using Ti-K edge X-ray absorption spectra.

\section{Experimental Procedure}

\subsection{Preparation of the Two-phase Borosilicate Glass Containing Titanium Oxide}

Since $\mathrm{B}_{2} \mathrm{O}_{3}$ can be concentrated in one of the phases during the spinodal decomposition of the borosilicate glass, the distribution of titanium oxides in the decomposed phases may depend on the $\mathrm{B}_{2} \mathrm{O}_{3}$ content in the initial glass compositions. Therefore, we prepared glass compositions with different $\mathrm{B}_{2} \mathrm{O}_{3}$ content to investigate the relationship between the distribution of titanium oxides in the decomposed phases and the initial glass compositions. The glass compositions designed for this study are shown in Table $\mathbf{1 .}$

We used silica, alumina, boron trioxide, titania (rutile phase), calcium carbonate and sodium carbonate (all provided by Waco Corp. as special grade chemicals) to prepare the glass samples.

$\mathrm{SiO}_{2}-\mathrm{Na}_{2} \mathrm{O}-\mathrm{B}_{2} \mathrm{O}_{3}-\mathrm{TiO}_{2}$ glasses were first prepared as mother glasses to prevent the evaporation of $\mathrm{Na}_{2} \mathrm{O}$ and $\mathrm{B}_{2} \mathrm{O}_{3}$ at high temperatures. Silica, boron trioxide, titania and sodium carbonate were mixed in a mortar and melted in a $\mathrm{Pt}-10 \% \mathrm{Rh}$ crucible in an $\mathrm{Ar}$ atmosphere for $2 \mathrm{~h}$ at $1373 \mathrm{~K}$.
The mother glasses were then produced by quenching the melt in water.

$\mathrm{SiO}_{2}-\mathrm{CaO}-\mathrm{Al}_{2} \mathrm{O}_{3}-\mathrm{Na}_{2} \mathrm{O}-\mathrm{B}_{2} \mathrm{O}_{3}-\mathrm{TiO}_{2}$ glasses were then prepared using silica, alumina, calcium carbonate and the $\mathrm{SiO}_{2}-\mathrm{Na}_{2} \mathrm{O}-\mathrm{B}_{2} \mathrm{O}_{3}-\mathrm{TiO}_{2}$ mother glasses. These materials were mixed in a mortar and melted in $\mathrm{Pt}-10 \% \mathrm{Rh}$ crucibles in an Ar atmosphere for $5 \mathrm{~h}$ at $1723 \mathrm{~K}$. The glass samples were obtained by quenching the melts in water and they were examined by X-ray diffraction analysis with a Rigaku RINT 2500 with $\mathrm{CuK} \alpha$ radiation at $40 \mathrm{kV}$ and $200 \mathrm{~mA}$ to confirm that they were glassy. To form spinodal decomposition, the glasses were heat-treated in air to $993 \mathrm{~K}$ and then cooled to room temperature. X-ray diffraction analysis was carried out on the heat-treated glasses to determine whether they retained their glass state.

To observe their microstructures, the heat-treated glass specimens were polished into less than $30 \mu \mathrm{m}$ in thickness using fine diamond particles $(15,9,6,3$ and $1 \mu \mathrm{m}$ in diameter) dispersed on plates. An Ar-ion milling was then conducted using a Gatan Model 691 with an ion-beam voltage of $4.2 \mathrm{kV}$ to make a hole in these specimens. The microstructures around the hole in the specimens were observed using a Hitachi H800 transmission electron microscope with an acceleration voltage of $200 \mathrm{kV}$ and a camera length of $1.2 \mathrm{~m}$. A compositional analysis by energy dispersion spectroscopy was performed using a scanning time of $30 \mathrm{~s}$ and a spot size of $20 \mathrm{~nm}$.

\subsection{Fabrication of Porous Glass Using Spinodal De- composition in Glass}

Porous glass containing titanium oxides was produced by leaching one of the decomposed phases in a two-phase borosilicate glass with an acid solution. One hundred milligram quantities of the two-phase glass samples were used after their bulk sizes were adjusted to less than $1 \mathrm{~mm}$ in diameter. The leaching process was performed by immersing the glass into $100 \mathrm{ml}$ of $1 \mathrm{M} \mathrm{HCl}$ solution at $353 \mathrm{~K}$ for $14 \mathrm{~h}$ in total and the acid solutions were refreshed after $7 \mathrm{~h}$ of immersion. Microstructures on the glass surfaces after leaching were observed using a Hitachi S-5200 field emission scanning electron microscope with an acceleration voltage of $15 \mathrm{kV}$. The elemental compositions of the glass dissolved in the acid solutions were analyzed with a Seiko SPS7800 inductively coupled plasma emission spectrometer.

\subsection{Structural Analysis of the Titanium Oxide Dis- persed in Glass}

Local structures of the titanium oxide species in the porous glass obtained by the spinodal decomposition of the borosilicate glass were determined by analyzing the Ti Kedge X-ray absorption near edge structure (XANES) spectra. These X-ray adsorption spectra were measured in fluorescence mode at the BL-7C facility of the Photon Factory

Table 1. Selected compositions of multicomponent borosilicate glass containing titanium oxides.

\begin{tabular}{|c|c|c|c|c|c|c|c|}
\hline & \multirow{2}{*}{\begin{tabular}{c}
$\mathrm{BO}_{1.5} \begin{array}{c}\text { content in glass } \\
{[\mathrm{mol} \%]}\end{array}$ \\
\cline { 3 - 8 }
\end{tabular}} & \multicolumn{6}{|c|}{ Composition [mol\%] } \\
\hline AT10 & 10 & 72.0 & 12.3 & 2.6 & 5.3 & 5.3 & 2.5 \\
\hline AT20 & 20 & 65.0 & 13.0 & 2.8 & 5.6 & 11.1 & 2.5 \\
\hline AT30 & 30 & 57.2 & 13.8 & 2.9 & 5.9 & 17.7 & 2.5 \\
\hline
\end{tabular}


at the National Laboratory for High-Energy Physics, Tsukuba, Ibaraki, Japan.

\section{Results and Discussion}

\subsection{Spinodal Decomposition in Multicomponent Borosilicate Glass}

Table 2 shows the appearance change of the glasses AT10, AT20 and AT30 with holding time at $993 \mathrm{~K}$. As the holding time increased, the transparent glasses gradually turned bluish and finally became opalescent. X-ray diffraction patterns for the glasses after heat-treatment for $96 \mathrm{~h}$ at $993 \mathrm{~K}$ are shown in Fig. 1. Since no crystalline peaks were detected in the diffraction patterns, the opaqueness was not attributed to the crystallization of glass.

Electron micrographs of the heat-treated glasses are shown in Fig. 2. Interconnected morphologies were observed in these glasses and they indicated spinodal decomposition. Since no evidence for crystalline phases was detected in the electron diffraction patterns for each specimen, as shown in Fig. 2, the annealed specimens were glassy in the microscopic observation area. In addition, the size of the microstructures in the glasses increased with higher initial $\mathrm{B}_{2} \mathrm{O}_{3}$ concentrations. Since $\mathrm{B}_{2} \mathrm{O}_{3}$ has a low melting point, the addition of $\mathrm{B}_{2} \mathrm{O}_{3}$ can decrease the softening temperature of the glass and can promote mass transfer to result in spinodal decomposition.

Table 2. Change in the appearance of the glasses with heattreatment time.

\begin{tabular}{|l|r|c|c|c|}
\hline \multirow{2}{*}{} & \multicolumn{4}{|c|}{ Holding time $[\mathrm{h}]($ Temperature: $993 \mathrm{~K})$} \\
\cline { 2 - 5 } & 0 (Untreated) & 24 & 48 & 96 \\
\hline AT10 & transparent $\rightarrow$ bluish transparent $\rightarrow$ adularescent \\
\hline AT20 & transparent $\rightarrow$ adularescent $\rightarrow$ opalescent $\rightarrow$ opalescent \\
\hline AT30 & transparent $\rightarrow$ adularescent $\rightarrow$ opalescent $\rightarrow$ opalescent \\
\hline
\end{tabular}

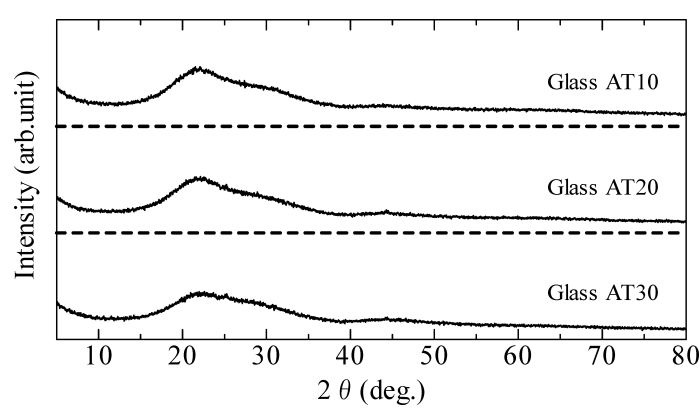

Fig. 1. X-ray diffraction patterns of glasses AT10, AT20 and AT30 annealed for $96 \mathrm{~h}$ at $993 \mathrm{~K}$.

\subsection{Distribution of Titanium Oxides in the Glass Phases Formed by Spinodal Decomposition}

Compositional analyses were carried out on the microstructures of the heat-treated glasses using energy dispersion spectroscopy to determine the compositions of the glass phases formed by spinodal decomposition. $\mathrm{Si}, \mathrm{Ca}$ and Ti were selected as elements for compositional analyses. The compositional analysis results of the decomposed phases in the annealed glass AT30 are shown in Fig. 3. One of the phases contained high proportion of $\mathrm{SiO}_{2}$ and it can remain intact during the acid leaching process to constitute the base structure of the porous glass. The other phase contained plenty of $\mathrm{CaO}$ and it can be leached in an acid solution. In this paper, the decomposed phase containing high proportion of $\mathrm{SiO}_{2}$ and the other phase containing plenty of $\mathrm{CaO}$ are referred to as Glass 1 and Glass 2, respectively. In addition, Fig. 3 indicates that Glass 1 contains a lower proportion of titanium oxides than Glass 2 .

To examine the relationship between the distribution of titanium oxides in the decomposed phases and the initial glass compositions, we assumed that the titanium oxides exist in glass at the tetrahedral coordination states as they substitute for silica in the glass matrix structure. Figure 4 shows the relationship between the molar proportions of $\mathrm{TiO}_{2}$ to $\mathrm{SiO}_{2}$ and $\mathrm{TiO}_{2}$ in the decomposed glass phases, and the $\mathrm{B}_{2} \mathrm{O}_{3}$ content in the initial glass compositions. In this figure, the proportions of $\mathrm{TiO}_{2}$ to $\mathrm{SiO}_{2}$ and $\mathrm{TiO}_{2}$ were obtained from the elemental analyses of the decomposed microstructures. Figure 4 shows that the proportion of $\mathrm{TiO}_{2}$

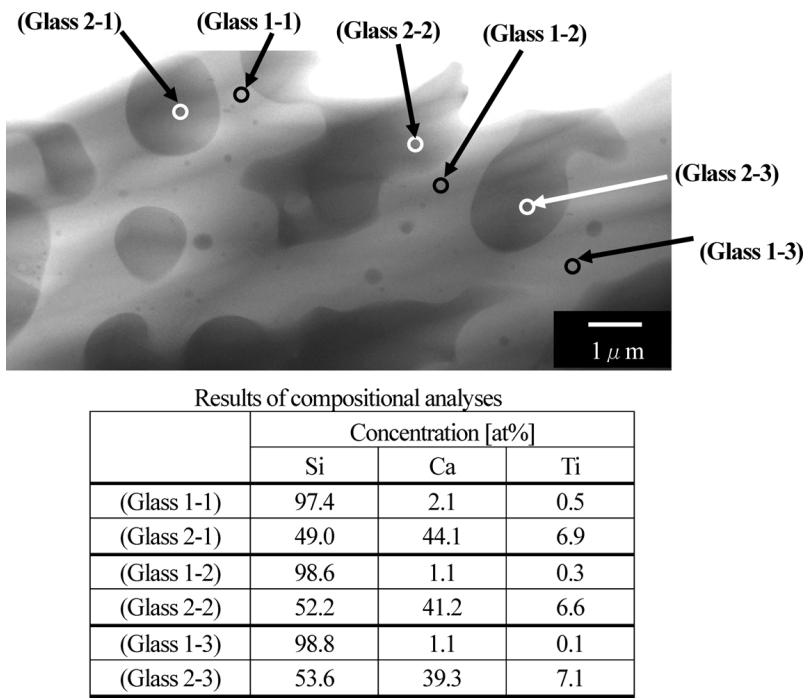

Fig. 3. Results of compositional analyses of the microstructure in glass AT30, heat-treated for $96 \mathrm{~h}$ at $993 \mathrm{~K}$
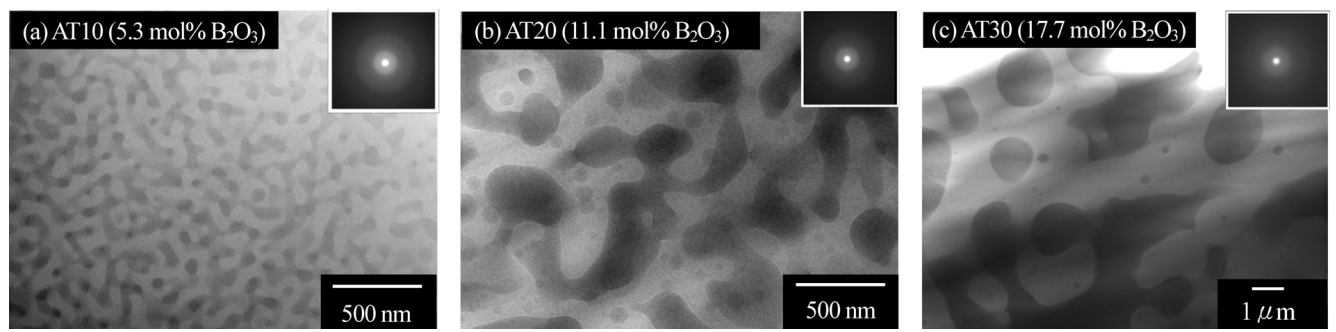

Fig. 2. Transmission electron micrographs of glasses annealed at $993 \mathrm{~K}$ for $96 \mathrm{~h}$ : (a) AT10; (b) AT20; (c) AT30. 


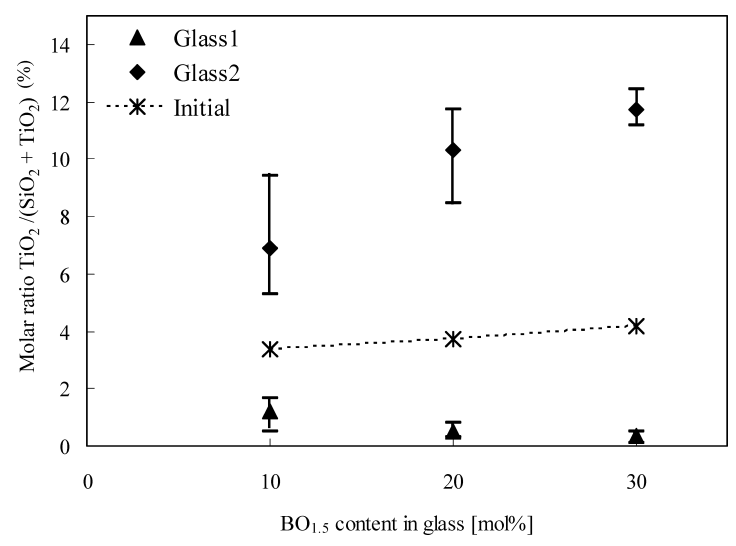

Fig. 4. Relationship between the proportions of $\mathrm{TiO}_{2}$ in $\mathrm{SiO}_{2}$ and $\mathrm{TiO}_{2}$, and the $\mathrm{B}_{2} \mathrm{O}_{3}$ content in the as-produced $\mathrm{SiO}_{2}-\mathrm{CaO}-\mathrm{Al}_{2} \mathrm{O}_{3}-\mathrm{Na}_{2} \mathrm{O}-\mathrm{B}_{2} \mathrm{O}_{3}-\mathrm{TiO}_{2}$ glass.

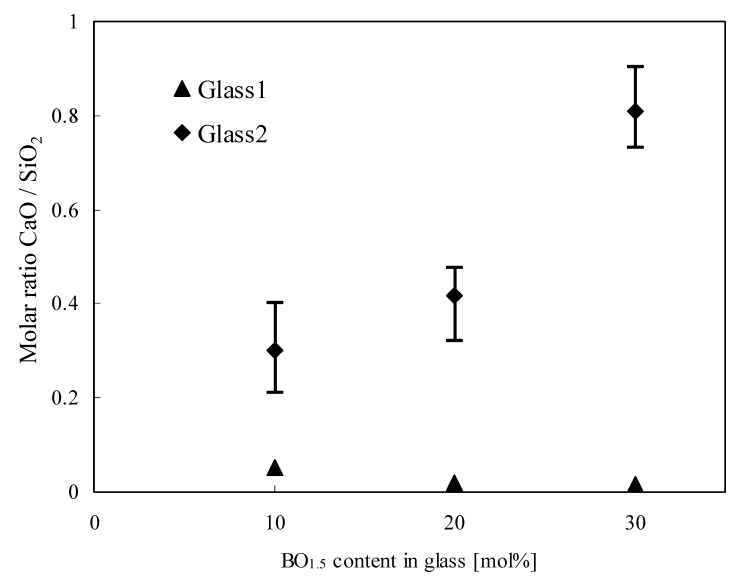

Fig. 5. Relationship between the molar composition ratios of $\mathrm{CaO}$ to $\mathrm{SiO}_{2}$ in the decomposed phases and the $\mathrm{B}_{2} \mathrm{O}_{3}$ content in the as-produced $\mathrm{SiO}_{2}-\mathrm{CaO}-\mathrm{Al}_{2} \mathrm{O}_{3}-\mathrm{Na}_{2} \mathrm{O}-\mathrm{B}_{2} \mathrm{O}_{3}-$ $\mathrm{TiO}_{2}$ glass.

increases slightly in Glass 1 as the $\mathrm{B}_{2} \mathrm{O}_{3}$ concentration in the initial glass composition decreases, while the proportion of $\mathrm{TiO}_{2}$ decreases in Glass 2. Therefore, the relative concentration of titanium oxides increases in Glass 1, which contains high proportion of $\mathrm{SiO}_{2}$, as the $\mathrm{B}_{2} \mathrm{O}_{3}$ concentration decreases in the initial glass composition. The relationship between the composition ratios of $\mathrm{CaO}$ to $\mathrm{SiO}_{2}$ in the decomposed phases and the $\mathrm{B}_{2} \mathrm{O}_{3}$ concentrations in the initial glasses compositions was also investigated as shown in Fig. 5. This indicates that the composition ratio of $\mathrm{CaO}$ to $\mathrm{SiO}_{2}$ in Glass 2 decreases as the $\mathrm{B}_{2} \mathrm{O}_{3}$ content in the initial glass composition decreases while the ratio in Glass 1 is kept approximately constant.

To determine the $\mathrm{B}_{2} \mathrm{O}_{3}$ concentrations in the decomposed glass phases, acid leaching was carried out on the heattreated borosilicate glasses. The chemical compositions of the remaining phase and the dissolved phase in the glass AT30 are summarized in Table 3. The remaining phase contained of high concentration of $\mathrm{SiO}_{2}$ and the dissolved phase contained $\mathrm{SiO}_{2}, \mathrm{CaO}$ and $\mathrm{B}_{2} \mathrm{O}_{3}$ as main components. These phases correspond to Glass 1 and Glass 2, respectively. The concentration of titanium oxides in the remaining phase was much lower than that in the dissolved phase and this corresponds to the compositional analysis of the microstructure in the heat-treated glass with energy disper-
Table 3. Compositions of dissolved and remaining phases in glass AT30.

\begin{tabular}{|c|c|c|c|c|c|c|}
\hline & \multicolumn{6}{|c|}{ Composition [mol\%] } \\
\cline { 2 - 7 } & $\mathrm{SiO}_{2}$ & $\mathrm{CaO}$ & $\mathrm{Al}_{2} \mathrm{O}_{3}$ & $\mathrm{Na}_{2} \mathrm{O}$ & $\mathrm{B}_{2} \mathrm{O}_{3}$ & $\mathrm{TiO}_{2}$ \\
\hline $\begin{array}{c}\text { Remaining phase } \\
\text { (Glass 1) }\end{array}$ & 87.6 & 0.0 & 5.2 & 7.0 & 0.0 & 0.2 \\
\hline $\begin{array}{c}\text { Dissolved phase } \\
\text { (Glass 2) }\end{array}$ & 31.3 & 32.7 & 1.4 & 3.9 & 25.6 & 5.1 \\
\hline
\end{tabular}

sion spectroscopy, as shown in Fig. 3.

\subsection{Thermodynamic Analysis on the Distribution of Titanium Oxides in the Separated Phases by Spin- odal Decomposition in Multicomponent Borosili- cate Glass}

A thermodynamic analysis was conducted to evaluate the distribution of titanium oxides in the glass phases formed by spinodal decomposition in the multicomponent borosilicate glasses. In the thermodynamic calculations, we regarded glass as a super-cooled liquid phase. Activities of $\mathrm{TiO}_{2}$ were calculated with the concentration of $\mathrm{TiO}_{2}$ in the $\mathrm{SiO}_{2}$ and the $\mathrm{SiO}_{2}-\mathrm{CaO}-\mathrm{B}_{2} \mathrm{O}_{3}$ super-cooled liquid phases, respectively, because the experimental results obtained indicated that one of the decomposed phases contains high concentration of $\mathrm{SiO}_{2}$ and the other phase includes $\mathrm{SiO}_{2}, \mathrm{CaO}$ and $\mathrm{B}_{2} \mathrm{O}_{3}$ as the main components, as shown in Table 3 . Therefore, the $\mathrm{SiO}_{2}$ super-cooled liquid phase corresponds to Glass 1 and the $\mathrm{SiO}_{2}-\mathrm{CaO}-\mathrm{B}_{2} \mathrm{O}_{3}$ super-cooled liquid phase corresponds to Glass 2 in the decomposed phases. The FactSage thermodynamic computation program and the latest thermodynamic databases for molten oxide systems, developed by Pelton et al., ${ }^{11)}$ were used to estimate the activities of $\mathrm{TiO}_{2}$ in the super-cooled liquid phase. The calculated activities of $\mathrm{TiO}_{2}$ at $973 \mathrm{~K}$ are shown in Fig. 6. The activities of $\mathrm{TiO}_{2}$ in the $\mathrm{SiO}_{2}-\mathrm{CaO}-\mathrm{B}_{2} \mathrm{O}_{3}$ super-cooled liquid phase containing three different compositions are described in this figure because, as shown in Fig. 5, the composition ratios of $\mathrm{CaO}$ to $\mathrm{SiO}_{2}$ decreased in the decomposed phase of Glass 2 as the $\mathrm{B}_{2} \mathrm{O}_{3}$ content in the initial glass decreased. Figure 6 shows that at constant $\mathrm{TiO}_{2}$ activity, the concentration of $\mathrm{TiO}_{2}$ in the glass phase decreases as the $\mathrm{SiO}_{2}$ content in the glass phase increases. This calculated result means that if the $\mathrm{SiO}_{2}$ and the $\mathrm{SiO}_{2}-\mathrm{CaO}-\mathrm{B}_{2} \mathrm{O}_{3}$ glass phases constitute separated phases by spinodal decomposition, there should be lower concentrations of $\mathrm{TiO}_{2}$ distributed in the $\mathrm{SiO}_{2}$ glass phase than in the $\mathrm{SiO}_{2}-\mathrm{CaO}-\mathrm{B}_{2} \mathrm{O}_{3}$ glass phase. In addition, the concentration of titanium oxides in the $\mathrm{SiO}_{2}-\mathrm{CaO}-\mathrm{B}_{2} \mathrm{O}_{3}$ super-cooled liquid phase decreases as the $\mathrm{SiO}_{2}$ concentration increases in this phase. This indicates that the proportion of titanium oxides should show a relative increase in the $\mathrm{SiO}_{2}$ glass phase as the composition ratio of $\mathrm{CaO}$ to $\mathrm{SiO}_{2}$ in the $\mathrm{SiO}_{2}-\mathrm{CaO}-\mathrm{B}_{2} \mathrm{O}_{3}$ glass phase decreases. Therefore, the above calculated results correspond to the experimental results obtained for the distribution of titanium oxides in the decomposed phases in multicomponent borosilicate glasses. 


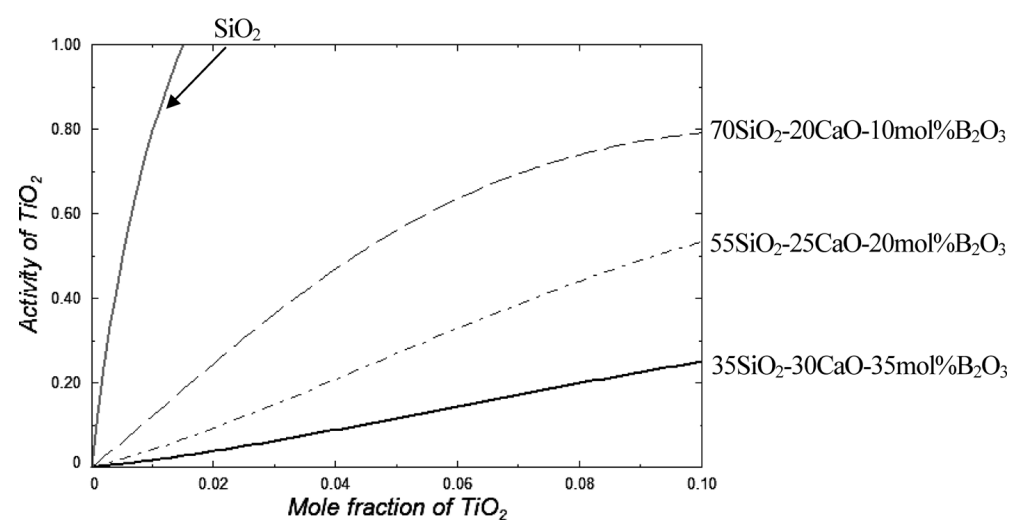

Fig. 6. Calculated activities of $\mathrm{TiO}_{2}$ in the glass phases formed by spinodal decomposition in multicomponent borosilicate glasses at $973 \mathrm{~K}$.
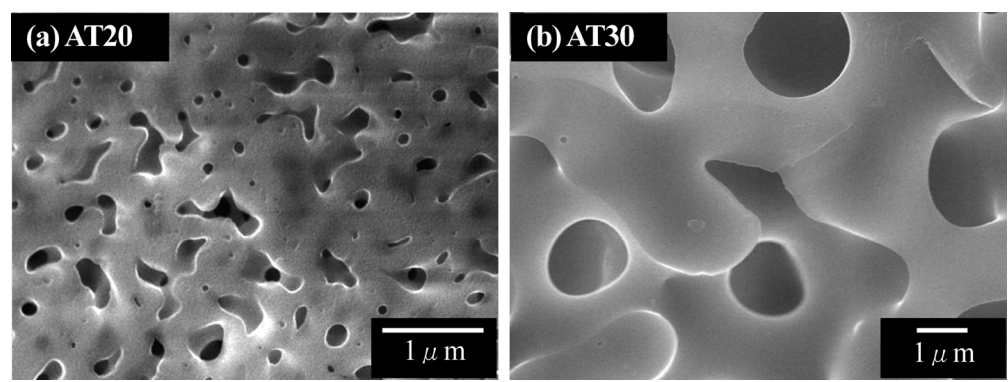

Fig. 7. Scanning electron micrographs on the surface of porous glasses obtained from spinodal decomposition in glass: (a) AT20, (b) AT30.

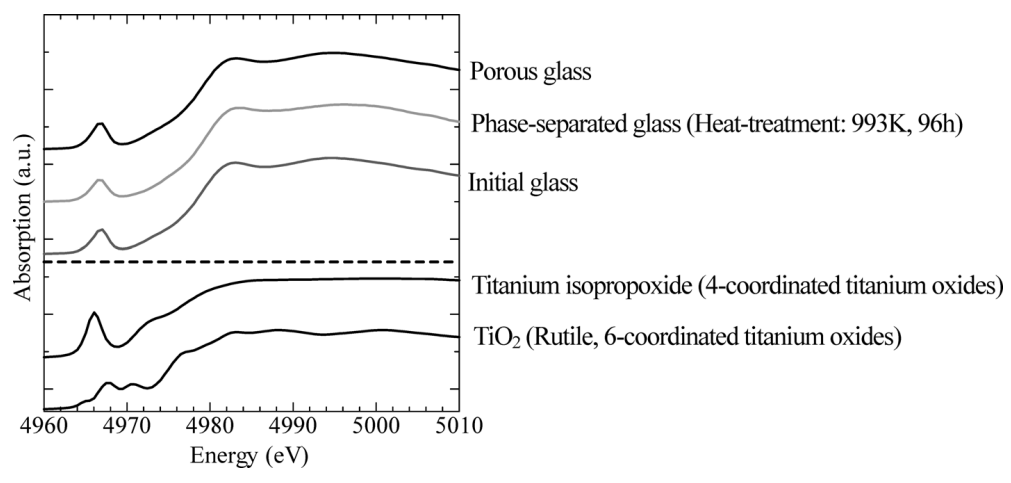

Fig. 8. Ti-K edge of XANES spectra of the multicomponent titanoborosilicate glass AT20.

\subsection{Fabrication of Porous Glass and Characterization of the Coordination State of Titanium Oxides in Porous Glass}

In this study, porous glasses were produced using twophase borosilicate glasses obtained from spinodal decomposition by removing one of the decomposed phases with acid solutions.

Figure 7 shows the microstructures in the porous glasses obtained from the borosilicate glasses AT20 and AT30. Three-dimensional interconnected microstructures are observed in those glasses and these microstructures correspond to the microstructures observed in annealed glasses, as shown in Fig. 2. Therefore, one of the decomposed phases in the heat-treated borosilicate glasses AT20 and AT30 was selectively leached with acid solutions. On the other hand, both the decomposed phases from the heattreated glass AT10 did not dissolve in an acid solution. It should be noted that AT10 initially contained lower concentration of $\mathrm{B}_{2} \mathrm{O}_{3}$ than AT20 and AT30. In addition, the microstructure formed by the spinodal decomposition of AT10 was very fine as shown in Fig. 2. Since fine microstructure can prevent glass components from diffusing in the acid solution, the solution can be locally saturated with glass components after it penetrates the microstructure. Therefore, it might be difficult to completely dissolve one of the decomposed phases in AT10 into an acid solution.

To determine the coordination state of titanium oxides in porous glass, the $\mathrm{Ti}-\mathrm{K}$ edge of the XANES spectra were measured. The measured spectra are shown in Fig. 8. The XANES spectra of titanium isopropoxide and titania in the rutile phase are shown in this figure as typical tetrahedral and hexahedral coordination states of titanium oxide. XANES spectra of the initial glass, heat-treated glass and porous glass obtained from AT20 correspond to that of titanium isopropoxide. This indicates that those glasses contain 
tetrahedrally coordinated titanium oxides, which might induce photocatalytic reactions such as in the removal of air pollutants.

\section{Conclusions}

The distribution of titanium oxides was examined in microstructures formed by the spinodal decomposition of multicomponent borosilicate glass wherein porous glass containing titanium oxides was produced. In the experimental study, multicomponent borosilicate glasses containing titanium oxides were produced by partially substituting $\mathrm{SiO}_{2}$ with $\mathrm{B}_{2} \mathrm{O}_{3}$ and small amounts of $\mathrm{TiO}_{2}$ in a $\mathrm{SiO}_{2}-\mathrm{CaO}-$ $\mathrm{Al}_{2} \mathrm{O}_{3}-\mathrm{Na}_{2} \mathrm{O}$ glass composition where the occurrence of spinodal decomposition has been previously confirmed. Interconnected microstructures that result from spinodal decomposition were detected in the borosilicate glass after heat-treatment. A compositional analysis of the microstructure using energy dispersion spectroscopy and analysis of the acid solutions after the leaching of these annealed glasses using inductively coupled plasma emission spectrometry revealed that one of the phases, separated by spinodal decomposition, contains high concentrations of $\mathrm{SiO}_{2}$ while the other phase contains $\mathrm{SiO}_{2}, \mathrm{CaO}$ and $\mathrm{B}_{2} \mathrm{O}_{3}$ as main components. We found that the concentration of titanium oxides in the glass phase with high $\mathrm{SiO}_{2}$ content is lower than that of the other phase but it increases as the $\mathrm{B}_{2} \mathrm{O}_{3}$ content in the initial glass decreases.

A thermodynamic analysis was carried out to evaluate the distribution of titanium oxides in the separated phases after the spinodal decomposition of the multicomponent borosilicate glass under the assumption that the glass is a super-cooled liquid phase. The calculated activities of titanium oxides in the decomposed glass phases indicated that, under constant $\mathrm{TiO}_{2}$ activity, the glass phase with higher $\mathrm{SiO}_{2}$ content can contain lower concentrations of $\mathrm{TiO}_{2}$. The calculated results correspond to the experimental results obtained for the distribution of titanium oxides in the decomposed glass phases shown above.

One of the phases formed by the spinodal decomposition of multicomponent borosilicate glasses was selectively re- moved with an acid solution and porous glasses with a three-dimensional interconnected structure were obtained. $\mathrm{X}$-ray absorption measurements revealed that the porous glass contains tetrahedrally coordinated titanium oxides.

\section{Acknowledgements}

This study was supported by Priority Assistance for the Formation of Worldwide Renowned Centers of ResearchThe Global COE Program (Project: Center of Excellence for Advanced Structural and Functional Materials Design) from the Ministry of Education, Culture, Sports, Science and Technology (MEXT), Japan. Observation of the microstructures in the samples by electron microscopy was carried out in a facility at the Research Center for Ultrahigh Voltage Electron microscopy, Osaka University, with the assistance of Professor Hirotaro Mori and Technical Official Eiji Taguchi. X-ray absorption measurements for the glasses containing titanium oxides were obtained by Professor Hiromi Yamashita and assistant professor Takashi Kamegawa, Division of Materials and Manufacturing Science, Graduate School of Engineering, Osaka University. We thank them most warmly for their assistance in this study.

\section{REFERENCES}

1) T. P. Seward, D. R. Uhlmann and D. Turnbull: J. Am. Ceram. Soc., 51 (1968), 278.

2) Y. Moriya, D. H. Warrington and R. W. Douglas: Phys. Chem. Glasses, 8 (1967), 19.

3) W. Haller, D. H. Blackburn, F. E. Wagstaff and R. J. Charles: J. Am. Ceram. Soc., 53 (1970), 34.

4) T. Nakashima and Y. Kuroki: Nippon Kagaku Kaishi, (1981), 1231.

5) M. Suzuki and T. Tanaka: ISIJ Int., 46 (2006), 1391

6) M. Suzuki and T. Tanaka: ISIJ Int., 48 (2008), 405.

7) M. Suzuki and T. Tanaka: ISIJ Int., 48 (2008), 1524.

8) M. Suzuki and T. Tanaka: J. Phys., Conf. Ser. 165 (2009), 012078.

9) H. Yamashita, Y. Ichihashi, M. Anpo, M. Hashimoto, C. Louis and M. Che: J. Phys. Chem., 100 (1996), 16041.

10) A. D. Pelton and M. Blander: Metall. Trans. B, 17B (1986), 805.

11) C. W. Bale, A. D. Pelton, W. T. Thompson and G. Eriksson: FactSage, Ecole Poly-technique, Montreal, (2001), http://www.crct. polymtl.ca. (Accessed on 27th, September, 2009) 